\title{
Factors associated with the recruitment of foreign nurses in Japan: a nationwide study of hospitals
}

\author{
Yuko O. Hirano ${ }^{*} \mathbb{E}$, Kunio Tsubota² and Shun Ohno ${ }^{3}$
}

\begin{abstract}
Background: Nurse migration under bilateral agreements is a recent global trend, although lack of consultation with the health industries has led to challenges in the recruitment of foreign nurses by hospitals. To analyze the prevailing perception of hospitals on the Economic Partnership Agreement (EPA), under which Japan opened the doors to foreign nurses, we surveyed hospitals that are yet to employ foreign nurses.

Methods: An anonymous questionnaire was developed and distributed to eligible hospitals; it assessed managers' perception of Japan's policy on the recruitment of foreign nurses and their intentions to hire foreign nurses under the EPA (hereafter called EPA nurses). We randomly selected 1879 hospitals, or $22 \%$ of the hospitals in Japan $(n=8540)$, with more than 20 beds. We used descriptive statistics, a Chi-square test, and logistic regression analysis to identify the predictors and developed a model to predict the likelihood of their intention to recruit EPA nurses in the future.

Results: In total, 432 hospitals were eligible for further analysis (response rate: 22.9\%). Half (50\%) of the hospital managers were considerably interested in Japan's policy on recruiting EPA nurses, although only $20 \%$ intended to recruit EPA nurses in the future. Willingness to recruit EPA nurses was associated with the degree of interest in the policy (OR 9.38; 95\% Cl 4.42-19.90) and managers' perception of EPA nurses (OR 5.32, 95\% Cl 2.38-11.89).

Conclusions: To attract more hospitals to recruit foreign nurses, it is essential for the Japanese government and the sending countries to review their EPA systems. Utilizing returning nurses to assist language acquisition by the forthcoming EPA nurses could be a provisional solution. For a more fundamental solution, long-term provision, from prior to their migration until their return migration, is needed to encourage brain circulation, as opposed to brain drain, between sending and receiving countries.
\end{abstract}

Keywords: Foreign nurse, Economic partnership agreement, Japan, Hospital

\section{Background}

Nurse migration under bilateral agreements is one of the recent global trends, which can be observed in South Africa [1], ASEAN countries [2], Mexico [3], and India [4], and it may affect the migration flow of nurses by rapidly expanding market activities [5]. Previous studies on

*Correspondence: hirano@nagasaki-u.ac.jp

${ }^{1}$ Institute of Biomedical Sciences, Nagasaki University, 1-7-1 Sakamoto, Nagasaki, Nagasaki 852-8520, Japan

Full list of author information is available at the end of the article nurse migration under bilateral agreements indicated that bilateral agreements offer the flexibility to enable easier negotiation and quicker resolutions [6] between the signed countries. It aims to improve the relationship and accelerate the trade between source and target countries [7]. It also increases the temporary migration of nurses who offer healthcare services to countries facing significant shortages of nurses [8]. However, nurse migration under bilateral agreements adversely affects nurses. For example, it may lead to potential de-skilling [9] and render them vulnerable to the global economic crisis original author(s) and the source, provide a link to the Creative Commons licence, and indicate if changes were made. The images or other third party material in this article are included in the article's Creative Commons licence, unless indicated otherwise in a credit line to the material. If material is not included in the article's Creative Commons licence and your intended use is not permitted by statutory regulation or exceeds the permitted use, you will need to obtain permission directly from the copyright holder. To view a copy of this licence, visit http://creativecommons.org/licenses/by/4.0/. The Creative Commons Public Domain Dedication waiver (http://creativeco mmons.org/publicdomain/zero/1.0/) applies to the data made available in this article, unless otherwise stated in a credit line to the data. 
$[3,10]$. Previous studies have indicated an insufficient involvement of health professionals in trade negotiations relating to public health $[8,11]$; this may adversely impact nurses and healthcare institutions. Therefore, it is important to analyze the provision of bilateral agreements from the perspective of the healthcare industry.

In this study, we analyzed nurse migration under the Economic Partnership Agreement (EPA), signed between Japan and Indonesia (in 2007), between Japan and the Philippines (in 2006), and between Japan and Vietnam (in 2008). As of January 2019, only 136 foreign registered nurses remained in Japan [12], which is merely $10.5 \%$ of the 1300 EPA nurse candidates who had entered Japan since 2008.

The flow of receiving EPA nurses is shown in Fig. 1. The qualifications and conditions for the eligibility criteria are stipulated in the EPAs signed between Japan and each of the source countries. Both applicants and the employer agree to the terms and conditions of training and work, and sign the contract. The employer pays a commission fee (131,400 yen per person) and a management fee (20,000 yen per person) to Japan International Corporation of Welfare Services (JICWELS), the only official agency for recruiting EPA nurses. Employers also pay 450 US dollars as agency fees to the Philippine Overseas Employment Administration of the Philippines for a Filipino nurse and the Department of Labor of Vietnam for a Vietnamese nurse. They pay 4055,000 Indonesian rupiahs (approximately 380,000 yen) to the National Board for the Placement and Protection of Indonesian Overseas Workers for an Indonesian nurse. In addition, Japanese language training fees, which costs 360,000 yen per person, are shouldered by employers [13]. Upon entry into Japan, EPA nurses are provided with a "Special Activities, Nurse Candidates" visa that is extensible for up to 3 years. After they pass the National Board Examination (NBE), they become entitled to the "Special Activities, Registered Nurse" visa, which can be extended indefinitely.

The focus of previous studies was that the system struggled to persuade EPA nurses to work as "nurse candidates" until they pass the NBE for nurses in the Japanese language to become "registered nurses" [14-17]. As "nurse candidates", they cannot fully conduct nursing interventions, which they did in their country of origin. This system may disappoint EPA nurses. In fact, obtaining a high level of proficiency in the Japanese language is one of the biggest challenges for EPA nurses [15, 16, 18]. Differences in language, aside from differences in culture-based lifestyle, are considered barriers to the adjustment of Filipino [19], Chinese [20], Jordanian [21], and nurses of different nationalities who migrate to other

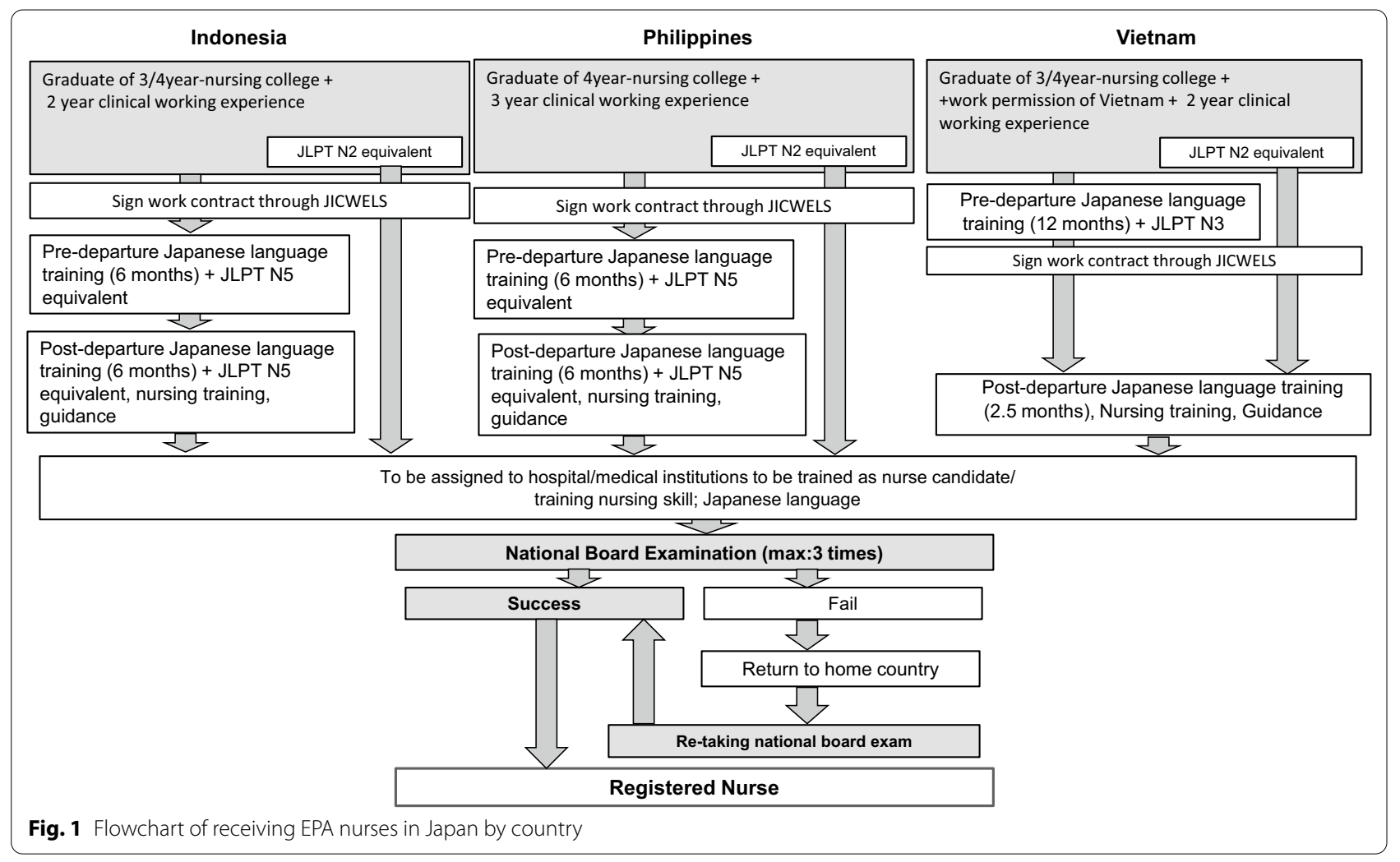


countries [22, 23]. Further, the language skills have been shown to affect pass rates for those taking the English licensure exam $[24,25]$, and this may be worse when the exam is conducted in Japanese, as the language is less commonly spoken worldwide. EPA nurses also require additional effort to prepare for NBE. However, Japanese language proficiency does not necessarily guarantee success on the NBE [26] since the examination questions are based on Japan's unique nursing practices [27]. For instance, Japan's nursing practice involves "basic nursing tasks" including bed bath and toileting, and such nursing practices are particularly important in Japan, which is a super-aged society.

It is noteworthy that the challenges are faced not only by the nurses, but also by the hospitals employing EPA nurses. Especially at the outset of EPA, they struggled with instructing EPA nurses to pass the NBE, which is affected by the level of Japanese language proficiency of the EPA nurses [18]. The hospitals also struggled with differences in socio-cultural contexts between Japan and the EPA nurses' countries of origin; such differences may widen the gaps in terms of nursing practice that diverges from the regulations or system of the country where these nurses originally worked [26]. This is a crucial detail when instructing EPA nurses to prepare for the NBE. This results in enormous costs to the hospitals, not only economically [28] but also psychologically [29], because they are responsible for assisting EPA nurses' training and education [30].

The authors assume that Japan's EPA, which underlies the "incompatibilities" between the right to employment and that to practice nursing [31], was not well consented by stakeholders [32, 33], especially at the outset of the EPA. Given sufficient information, the employment status of nurses would be well consented, and recruitment of EPA nurses would be better implemented. In this study, we analyzed the challenges of the EPA from the perspective of the hospital management. The study population included hospitals that had never accepted EPA nurses until the time of conducting the survey. This is due to the following reasons. First, some managers accepted EPA nurses after being asked by the Ministry of Health, Labour and Welfare (MHLW) to fill the EPA quota so they might receive benefits from the government that enable them to maintain a position of prestige in the medical community in Japan. They may be reluctant to disclose problems related to EPA nurses and may even disregard them because they wish to maintain links with the government [31]. Contrarily, hospitals that do not accept EPA nurses may express their perceptions more candidly, as they are not loyal to the government. Second, hospitals that do not accept EPA nurses may express their perceptions freely, which widens our view on recruiting
EPA nurses. However, only a few studies have been conducted on this study population to investigate factors associated with the employment of EPA nurses in terms of hospital management. This study investigated the EPA policy by analyzing the perceptions of the hospital managers who have not yet employed EPA nurses. They need not surmise the intentions of the government; therefore, they can express their perceptions freely and objectively evaluate the advantages and disadvantages of the EPA without any constraints.

\section{Methods}

This study aims to investigate the factors associated with the recruitment of EPA nurses among managers of hospitals in Japan who have not previously employed these nurses. A questionnaire was developed and distributed to the hospitals randomly selected from the stratified target population.

\section{Respondents}

Respondents included managers in Japanese hospitals that had not employed EPA nurses. The lists of registered hospitals in each prefectural branch of MHLW were used for sampling. The selection criterion used the number of hospitals per prefecture. We selected hospitals with more than 20 beds to meet the condition of the JICWELS [34]. Questionnaires were mailed to 2000 selected hospitals. Of these, 121 questionnaires did not reach their destination, because of closure or removal. The rate of sampling, therefore, was $22 \%$ (1879 of 8540 hospitals registered in Japan).

\section{Instruments}

We developed an 8-page questionnaire by examining previous similar surveys on hospitals that employed EPA nurses and unpublished interviews conducted by the research team. The questionnaire contained questions about the following: (1) the attributes of the hospitals, including their type (privately owned hospitals enacted by Medical Care Act Article 6 and publicly owned hospitals enacted by Medical Care Act Article 31) and the number of beds; (2) the possible factors that may affect the decision of recruiting EPA nurses (independent variables), including the difficulties in recruiting Japanese nurses, knowledge on recruiting EPA nurses, perceptions of EPA nurses, and perceptions of Japan's policy on recruiting EPA nurses; and (3) the degree of willingness to recruit EPA nurses under the EPA program (dependent variable). The perception of EPA nurses was asked with respect to eight items on a four-point Likert-type scale (ranging from $1=$ not agree at all to $4=$ fully agree). The item scores were aggregated to an "image score" to represent the image of EPA nurses. The content validity 
was examined by the research team through discussions, and reliability was examined by Cronbach's alpha. Respondents were divided into two groups by the average image score.

As for the policies on EPA nurses, respondents were asked about their views on the nine items listed in Table 2 and answered with a four-point Likert-type scale (ranging from $1=$ do not agree at all to $4=$ strongly agree). Willingness to recruit EPA nurses in the future under the EPA was measured on a four-point Likert-type scale (ranging from $1=$ not at all to $4=$ definitely will). Respondents were divided into two groups with average scores: those who were likely to recruit and those who were not.

\section{Data analysis}

We used IBM SPSS Statistics for Windows, Version 25J for the statistical analyses. Descriptive statistics were used for the characteristics of hospitals and respondents, and Chi-square tests were used to test the correlation between the willingness to recruit EPA nurses, the attributes, and each independent variable. A logistic regression analysis was used to identify factors influencing willingness to recruit EPA nurses in the future. To develop the econometric model, eligible independent variables, selected from previous studies, were chosen from the list of perceptions on the government policy regarding the recruitment of EPA nurses, image score, and current conditions of recruiting Japanese nurses $[18,26,28,29$, $35]$. The independent variables were selected from the results of the Chi-square tests, which revealed statistical associations with dependent variables such as the intention to recruit EPA nurses in the future to be significant. A stepwise method was used to select the independent variables to develop the most appropriate models. The level of statistical significance was set at $p<0.05$.

\section{Ethical considerations}

Ethics approval was granted by the Biomedical Sciences Ethics Board at Nagasaki University (Permission number: 18030817).

\section{Results}

\section{Respondents}

A total of 485 hospital managers responded to questionnaires. Of these, 53 hospitals were excluded because they had either employed EPA nurses or did not answer the question. In total, 432 samples were analyzed (respondent rate: $23.0 \%$ ) (Table 1 ).

\section{Managers' perception of EPA nurses}

Approximately $96.3 \%$ of the hospital managers felt that training EPA nurses would be difficult, that EPA nurses found it difficult to master the Japanese language by working (94.8\%), and that very few passed the NBE (93.4\%). A large proportion also thought that accepting EPA nurses was costly (61.9\%). However, a few managers thought that EPA nurses had high nursing skills (33.3\%), acquired good reputations among patients and families (27.3\%), remained in Japan for a long time (25.1\%), and adjusted easily to Japanese hospitals (22.6\%). Neither the type/size of hospitals nor the managers' profession were significantly associated with the willingness to recruit EPA nurses. Therefore, in the following part of this study, we did not divide hospitals by type or size and did not view the manager's profession as an influencing factor.

The mean image score was 15.17 (standard deviation $[\mathrm{SD}]=2.98$ ) with a minimum of eight and a maximum of 25. Cronbach's alpha was 0.636 . We divided the image score into two groups: lower image (less than 14) and higher image ( 15 or above).

\section{Perception of policy reform on recruitment of EPA nurses} The respondents' perception of policy reform for EPA nurses is shown in Table 2 (left side).

\section{Chi-square test}

The results of the Chi-square test indicated that willingness to recruit EPA nurses was significantly correlated with perceived difficulties in recruiting Japanese nurses $(p=0.040)$, image score $(p<0.001)$, and degree of interest in Japan's policy on EPA nurses $(p<0.001)$. The result of the Chi-square test between perception on policy and willingness to recruit EPA nurses in the future is shown in Table 2 (right side).

\section{Logistic regression analysis}

Table 3 presents the final model of logistic regression, which was significant $(p<0.0001)$ and accounted for $37.6 \%$ of the variance (Nagelkerke $R^{2}=0.376$ ).

\section{Discussion}

Although the respondents had not employed EPA nurses previously, they offered several insights to identify the problems with and improve the policies on EPA nurses. The EPA nurse policies are not widely known, and hospitals in Japan are not adequately informed of them. Only $20 \%$ of the respondents answered that they wish to recruit EPA nurses. However, this does not necessarily mean that the rest are not interested in EPA nurses at all, as half $(50 \%)$ of the respondents answered that they are interested in the government's policy on EPA nurse recruitment. Given that over $80 \%$ of the respondents found it very hard/hard to recruit Japanese nurses, it may be interpreted that half of the respondents carefully monitor EPA policies, wondering if the current system would help fill the shortage of nurses. As such attitudes toward 
Table 1 Characteristics of the respondents and willingness to recruit EPA nurses $(n=432)$

\begin{tabular}{|c|c|c|c|c|}
\hline Item & $n$ & (\%) & $\begin{array}{l}\text { Willingness to recruit EPA } \\
\text { nurses }\end{array}$ & $p$ value \\
\hline \multicolumn{5}{|l|}{ Respondents } \\
\hline Directors/CEOs & 166 & 38.4 & 22.6 & \multirow[t]{3}{*}{0.651} \\
\hline Managers & 163 & 38.2 & 18.9 & \\
\hline Head nurses & 98 & 23.0 & 19.4 & \\
\hline \multicolumn{5}{|l|}{ Type of hospital } \\
\hline Private hospitals & 381 & 88.2 & 21.0 & \multirow[t]{3}{*}{0.113} \\
\hline Public hospitals & 50 & 11.6 & 12.5 & \\
\hline N.A & 1 & 0.2 & & \\
\hline \multicolumn{5}{|l|}{ Number of beds } \\
\hline Less than 99 & 305 & 70.6 & 18.3 & \multirow[t]{3}{*}{0.211} \\
\hline $100-499$ & 116 & 26.9 & 25.2 & \\
\hline 500 and above & 11 & 2.5 & 10.0 & \\
\hline \multicolumn{5}{|l|}{ Recruiting Japanese nurses } \\
\hline Very hard/hard & 347 & 80.3 & 21.8 & \multirow[t]{3}{*}{0.047} \\
\hline Not so hard/not hard & 75 & 17.4 & 12.5 & \\
\hline N.A & 10 & 2.3 & & \\
\hline \multicolumn{5}{|l|}{ Knowledge about EPA } \\
\hline Know very much/much & 136 & 31.5 & 19.4 & \multirow[t]{3}{*}{0.473} \\
\hline Not so much/not at all & 292 & 67.6 & 20.3 & \\
\hline N.A & 4 & 0.9 & & \\
\hline \multicolumn{5}{|c|}{ Interest in policies on EPA nurses } \\
\hline Very much/much & 216 & 50.0 & 34.9 & \multirow[t]{3}{*}{$<0.0001$} \\
\hline Not so much/not at all & 211 & 48.8 & 4.8 & \\
\hline N.A & 5 & 1.2 & & \\
\hline \multicolumn{5}{|c|}{ Willingness to recruit EPA nurses in the future } \\
\hline Very much/much & 86 & 20.4 & - & - \\
\hline Not so much/not at all & 336 & 79.6 & - & - \\
\hline N.A & 10 & 2.3 & & \\
\hline
\end{tabular}

Table 2 Perception of EPA policy reform by degree of intention to recruit EPA nurses $(n=432)$

\begin{tabular}{|c|c|c|c|c|}
\hline \multirow[t]{2}{*}{ Perception of reform measures } & \multirow{2}{*}{$\begin{array}{l}\text { Perceptions } \\
\text { of the reform } \\
\text { measures } \\
\text { Strongly agree/agree }\end{array}$} & \multicolumn{3}{|c|}{$\begin{array}{l}\text { Willingness to recruit EPA nurses } \\
\text { in the future }(n=432)\end{array}$} \\
\hline & & $\begin{array}{l}\text { Strongly } \\
\text { agree/agree } \\
(\%)\end{array}$ & $\begin{array}{l}\text { Not agree/ } \\
\text { not at all } \\
\text { (\%) }\end{array}$ & $p$ value \\
\hline $\begin{array}{l}\text { Require nurses to pass certain level of Japanese language test before coming to } \\
\text { Japan }\end{array}$ & 85.5 & 19.1 & 80.9 & 0.067 \\
\hline Support hospitals in preparing nurses for the NBE & 83.5 & 17.9 & 81.1 & 0.006 \\
\hline Require EPA nurses who pass the NBE to stay for several years & 82.8 & 21.3 & 78.7 & 0.272 \\
\hline Organize to introduce EPA nurses to combat the shortage of nurses & 70.8 & 26.1 & 73.9 & $<0.0001$ \\
\hline $\begin{array}{l}\text { Invite private agencies under government supervision to stimulate the principle of } \\
\text { market mechanism }\end{array}$ & 58.1 & 22.6 & 77.4 & 0.115 \\
\hline $\begin{array}{l}\text { Admit the multi-recognition of nursing licenses between Japan and the partner } \\
\text { countries }\end{array}$ & 56.8 & 26.5 & 73.5 & $<0.0001$ \\
\hline Admit jun-kangoshi (certified prefectural nurses) under the EPA & 48.6 & 26.9 & 73.1 & 0.001 \\
\hline Prepare EPA nurses to pass the NBE & 38.4 & 28.8 & 71.2 & 0.001 \\
\hline $\begin{array}{l}\text { Not require EPA nurses to pass the NBE, but to accept them as Japanese nurses' } \\
\text { assistants }\end{array}$ & 32.4 & 25.9 & 74.1 & 0.037 \\
\hline
\end{tabular}


Table 3 Factors affecting the willingness to recruit EPA nurses

\begin{tabular}{|c|c|c|c|}
\hline Factors & OR & $(95 \% \mathrm{Cl})$ & $p$ value \\
\hline Interest in policies on EPA nurses & 9.38 & $(4.42-19.90)$ & $<0.001$ \\
\hline Image score & 5.32 & $(2.38-11.89)$ & $<0.001$ \\
\hline The Japanese government should articulate to introduce EPA nurses to overcome the shortage of nurses & 3.09 & $(1.38-7.51)$ & 0.013 \\
\hline $\begin{array}{l}\text { The Japanese government should admit the mutual recognition of nursing licenses between Japan and the } \\
\text { partner countries }\end{array}$ & 1.89 & $(1.01-3.53)$ & 0.048 \\
\hline
\end{tabular}

EPA nurses were observed regardless of type and size of the hospitals, or the managerial position of the respondents, and it seems that this perception is widely shared by hospitals in Japan.

One of the strongest factors associated with hesitation toward EPA nurses is their image. The image score mirrors a conviction of hospital staff that EPA nurses would encounter various difficulties arising from their limited Japanese language proficiency, which is crucial for their daily hospital work and for passing the NBE. We assume that there are some prejudices against EPA nurses. The respondents seem to be unaware of the many EPA nurses that had acquired a good reputation among patients and families. In fact, $75 \%$ of the hospitals that employed the first batch of Indonesian nurses in 2008 were satisfied or very satisfied with them because they had a bright personality $(92.9 \%)$ and an appropriate attitude toward patients (89.3\%) [35]. We assume that biases against EPA nurses are not the EPA nurses' responsibility, but of the EPA system. The low Japanese language proficiency of EPA nurses may be due to an inadequate time period set for pre-departure Japanese language training. This is particularly true among nurses of the first, second, and third batches of nurses from Indonesia and the first and second batches from the Philippines, who were not given any pre-departure Japanese language training. It may be that the image scores of this study reflect the shortcomings of the EPA in the early stages. Vietnamese nurses, who have 12 months of pre-departure Japanese language training, have higher language proficiency. Therefore, they have fewer language problems than Indonesian or Filipino nurses. In this light, the governments of Japan and the sending countries are recommended to employ returning EPA nurses to teach the Japanese language and provide information on Japan's unique nursing practices to the incoming EPA nurses, so that they will be well prepared to work and train in Japan. This may lessen the economic and psychological burden of hospitals.

This study also revealed the crucial conditions of hospitals that were struggling with a shortage of nurses. Twenty percent of the hospitals answered that they wished to recruit EPA nurses because they found it very hard/hard to recruit Japanese nurses. We assume that the hospitals attempted to employ EPA nurses to alleviate the shortage of Japanese nurses. A mid-term report released by MHLW [36] indicated that nursing shortages are especially severe in rural Japan. Hospitals in rural regions are assumed to be more likely to substitute EPA nurses for Japanese nurses than those in big cities, such as the Tokyo area. Regional differences cannot be proved by our survey because, due to the anonymity of the questionnaire, we could not identify the location of the hospitals. However, we take the excerpt from the narrative of a doctor respondent, who called the researchers to add comments on the survey, to strengthen the hypothesis. The respondent was the owner of a small private hospital but unfortunately was not successful in recruiting EPA nurses because nurses prefer to work in hospitals in the big cities. He expressed his opinion to the first author (HY) as follows: "I think the Japanese government should invite more EPA nurses to Japan. Please tell the government that there are some small-sized hospitals, especially in rural areas, that badly needs nurses. Even those who are from abroad will do to maintain our hospital to secure the health of people in this region."

However, the current EPA system does not seem to be effective in solving the imminent problems of hospitals. The EPA sets a quota of 200 nurses per country per year, which falls well short of the deficit of nurses. The country needs at least 30,000 nurses by the year 2025 [37]. Nurses are needed in Japan, especially in rural areas, although EPA regulations seem not to secure them effectively. Therefore, a fundamental solution must be implemented.

Recently, hospitals in Japan interested in recruiting EPA nurses have noticed a higher number of Chinese nurses being hired through private agencies. The actual number of Chinese nurses is unclear, as the Japanese government does not disclose the nationality of persons who obtain "medical visas", although the number of visas issued has been increasing. This phenomenon assumes that many Japanese hospitals are not satisfied with the system of recruiting nurses under the EPA and are thereby seeking other means of recruiting foreign nurses. Nearly $60 \%$ of the respondents of this study agreed to invite private agencies to the EPA under the supervision of the government to stimulate the principle of market mechanism, 
regardless of their intention of recruiting EPA nurses. The idea of implementing other means to address the manpower shortage seems to be widely accepted by hospitals nationwide. This is exemplified by the fact that the Japan Hospital Association, one of the biggest associations of hospitals in Japan, introduced the International Medical Human Resource Foundation in its website [38], a recruitment agency of Chinese nurses for member hospitals that claims to "provide a better service than the EPA". According to the foundation [39], they recruit eligible Chinese nursing students to be educated in the Japanese language for 1 to 3 years prior to entering Japan. After entry, the Chinese nurses will enroll in Japanese language schools to improve their language skills to pass the N1 level (the ability to understand Japanese used in a variety of circumstances [40]) of the Japanese Language Proficiency Test to be eligible to take the NBE. After they pass the NBE, they can work in Japanese hospitals as registered nurses. Contrary to JICWELS, who clearly stated the recruitment costs and previous NBE passing rates of EPA nurses, these private agencies did not disclose such key information. Therefore, the authors are careful not to judge this business model prematurely, as many counties reported problems caused by improper nurse recruitment [41, 42]. Nonetheless, these recruitment agencies seem to be attracting more hospitals because Chinese nurses can read Chinese characters in the NBE, thereby presenting higher passing rates than EPA nurses. The new business model also attracts nurses. Since they are not entering Japan under the EPA, Chinese nurses are offered a "medical visa". The visa is unlimited and allows nurses to work more flexibly than the "Special Activities, Registered Nurse" visa issued to EPA nurses. This flexibility is an advantage of the business.

Given these conditions, it is understandable that hospitals in Japan would be attracted to this model because, as shown in this study, $82.2 \%$ of the hospitals, regardless of their intention of recruiting EPA nurses, agreed with the statement "The Japanese government should require EPA nurses who pass the NBE to stay for several years." This represents the severe need of the hospitals suffering from the shortfall of nurses. They wish for nurses to work for as long as possible. If nurses are given visas that permit more flexible work, they would spend more time working in Japan. If Japan wishes to employ more EPA nurses, attracting more hospitals by reviewing the EPA scheme so that it would satisfy the needs of the hospitals is key. As the logistic regression model indicates, the more hospitals that are interested in the EPA, the more chances they take to recruit EPA nurses.

However, the Japanese government does not seem keen to fill the nursing job vacancies with EPA nurses. We assume that the MHLW, who is in charge of monitoring the EPA nurses' recruitment, cannot articulate the need to introduce EPA nurses to secure the nurse labor force, even though they know that there is a nursing labor shortage, as per their estimation [37].

Yeats et al. underscored that bilateral agreements offer governments more control and regulatory discretion [6]. As long as the government of Japan denies the recruitment of foreign labor in the name of immigration policy [43], it can only explain the significance of the present EPA as follows: "introducing EPA nurses is not to combat the shortage of nurses in Japan, but to respond to the request of the partner countries to accept the nurses" [30]. However, the statement is not helpful in assisting hospitals with nurse shortages, especially in rural regions [36]. Its ambiguity also confuses Japanese taxpayers, who paid more than 380,000,000 yen per year [44] in 2016 toward the costs of EPA nurses. It is, therefore, necessary for the Japanese government to make clear that the main purpose of bringing EPA nurses to Japan is to address the shortage of nurses.

\section{Limitations}

This study is not immune to respondent bias. The majority of participants were from privately owned hospitals (88.2\%) and small institutions with fewer than 99 beds (70.6\%). Recruiting foreign nurses will help to secure the nurse supply and reduce the risk of building an "inefficient medical service system" that was set out in the mid-term report published by the National Committee for Social Security in 2008 [45]. The report called for changes in hospitals in Japan, the majority of which are small privately owned hospitals with too few medical staff. Further research, including publicly owned hospitals equipped with more beds, is therefore needed to confirm these results.

\section{Conclusion}

This study revealed that the current EPA system is not the solution to counter the deficiency of nurses in Japan. This is because, as a form of trade agreement, the governments treat EPA nurses as a commodity [9]. In bartering Toyota cars with Filipino nurses and liquified petroleum gas with Indonesian nurses, they disregard the challenges of hospitals as well as those of EPA nurses. Similarly, Latin American nurses who migrated to Spain under the bilateral trade agreements realized that credential approvals were not transparent [10]. The trade agreement, as discussed above, sometimes confuses hospitals and nurses of the receiving countries, as it prioritizes accelerating the relationship with other countries in the global economy. Therefore, there may not be harmony in policy decisions that can achieve both health policy goals and economic trade goals [8]. 
Notably, EPA may also be harmful to the source countries because the health workforce strategies of their governments, focused on exports, may frustrate the efforts to ensure an adequate workforce of nurses [6, 17]. Better inclusion of trade agreement provisions into domestic health care policies is suggested. For instance, integrating the nurse education sector and labor market dynamics of both the sending and receiving countries can be a solution. The authors recommend that the Japanese government, in cooperation with nurse sending countries, develop the educational institutions in each sending country, to train nurses in fields in which Japan has good practices (i.e., gerontology nursing or psychiatry nursing). This may contribute to enhancing the opportunities of graduates of such institutions to remain in their country, which is becoming an aged society, or go to other destination countries, including Japan (through the EPA), with highly skilled nursing. Furthermore, facilitating returning migrants [46] should also be considered. Under such a longterm provision, this system may contribute to avoiding de-skilling and brain drain, but rather encourage brain circulation between sending and receiving countries. Simultaneously, the Japanese government is recommended to alleviate the regional shortage of nurses by subsidizing hospitals, particularly in rural areas, to raise the basic salary and compensations of nurses, regardless of their nationality, so that they can practice in more decent working conditions. Both international and domestic intervention are crucial for developing fundamental solutions to create a sustainable health workforce.

\section{Abbreviations}

EPA: Economic Partnership Agreement; JICWELS: Japan International Corporation of Welfare Services; NBE: National Board Examination.

\section{Acknowledgements}

We thank those who participated in our study.

\section{Authors' contributions}

$\mathrm{YH}$ developed the questionnaire and conducted the analysis and basic writing. $\mathrm{SO}$ and $\mathrm{KT}$ advised $\mathrm{YH}$ in developing the questionnaire. All authors read and approved the final manuscript.

\section{Funding}

This research was supported by the Ministry of Education, Science, Sports and Culture, Grant-in-Aid for Scientific Research (B), 2014-2018 (26293113).

\section{Availability of data and materials}

Data will be released upon completion of the study and is available upon reasonable request from the first author.

\section{Ethics approval and consent to participate}

Ethics approval was granted by the Biomedical Sciences Ethics Board at Nagasaki University (Permission number: 18030817).

\section{Consent for publication}

Not applicable.

\section{Competing interests}

The authors declare that they have no competing interests.

\section{Author details}

${ }^{1}$ Institute of Biomedical Sciences, Nagasaki University, 1-7-1 Sakamoto, Nagasaki, Nagasaki 852-8520, Japan. ${ }^{2}$ The Nippon Agricultural Research Institute, 3-29. Kioi-cho, Chiyoda-ku, Tokyo 102-0094, Japan. ${ }^{3}$ Seisen University, 3-16-21, Higashigotanda, Shinagawa-ku, Tokyo 141-8642, Japan.

Received: 29 June 2020 Accepted: 2 November 2020

Published online: 10 November 2020

\section{References}

1. Labonté R, Sanders D, Mathole T, Crush J, Chikanda A, Dambisya Y, Runnels V, Packer C, MacKenzie A, Murphy GT, Bourgeault IL. Health worker migration from South Africa: causes, consequences and policy responses. Hum Resour Health. 2015;13:92. https://doi.org/10.1186/s1296 0-015-0093-4.

2. Manning C, Sidorenko A. The regulation of professional migration: insights from the health and IT sectors in ASEAN. World Econ. 2007;30(7):1084-113. https://doi.org/10.1111/j.1467-9701.2007.01013.x.

3. Squires A. The North American Free Trade Agreement (NAFTA) and Mexican nursing. Health Policy Plan. 2011;26(2):124-32. https://doi. org/10.1093/heapol/czq024.

4. Walton-Roberts M. International migration of health professionals and the marketization and privatization of health education in India: from push-pull to global political economy. Soc Sci Med. 2015;124:374-82. https://doi.org/10.1016/j.socscimed.2014.10.004.

5. Kingma M. Nurses on the move: migration and the global health care economy. Ithaca: Cornell University Press; 2006. p. 142.

6. Yeates N, Pillinger J. International healthcare worker migration in Asia Pacific: international policy responses. Asia Pac Viewp. 2018;59(1):92-106. https://doi.org/10.1111/apv.12180.

7. Al Faithrich $\mathrm{CN}$, Tatlonghari VM. An empirical assessment of the effects of the Japan-Philippine Economic Partnership Agreement (JPEPA) on Philippine exports to Japan: a gravity model approach. J Econ Struct. 2018;7:31. https://doi.org/10.1186/s40008-018-0129-8.

8. Kidgell D, Hills D, Griffiths D, Endacott R. Trade agreements and the risks for the nursing workforce, nursing practice and public health: a scoping review. Int J Nurs Stud. 2020. https://doi.org/10.1016/j.jinurstu.2020.10367 6.

9. Ford M, Kawashima K. Regulatory approaches to managing skilled migration: Indonesian nurses in Japan. Econ Labor Relat Rev. 2016;27(2):23147. https://doi.org/10.1177/1035304616629580.

10. Pastor-Bravo M, Nelson S. Migration of Latin American nurses to Spain 2006-2016: a case study. Int Nurs Rev. 2019;66(2):183-90. https://doi. org/10.1111/inr.12511.

11. Jarman $\mathrm{H}$. Trade policy governance: what health policymakers and advocates need to know. Health Policy. 2017;121:1105-12. https://doi. org/10.1016/j.healthpol.2017.09.002

12. Koseiroudousyou: EPA ni motozuku gaikokujin kangoshi kaigofukushishi nado no genjo, (Ministry of Health, Labour and Welfare: current condition of foreign nurses and certified care worker candidates under EPA) (unpublished paper).

13. Japan International Corporation of Welfare Services, Heisei 30-nendo ban EPA ni motozuku kangoshi kouhosha ukeire no tebiki (Guide to accepting EPA nurse candidate's fiscal year 2018). https://jicwels.or.jp/files /EPA_H30_N.pdf. Accessed 13 Aug 2020. (Japanese only).

14. Yagi N, Mackey TK, Liang BA, Gerlt L. Policy review: Japan-Philippines Economic Partnership Agreement (JPEPA) —analysis of a failed nurse migration policy. Int J Nurs Stud. 2014;51:243-50. https://doi.org/10.1016/j.jijnur stu.2013.05.006.

15. Vilog RBT, Arroyo MKHD, Raquinio TGG. Empowerment issues in Japan's care industry: narratives of Filipino nurses and care workers under the Economic Partnership Agreement (EPA) labor scheme. Int J Asia Pac Stud. 2020;16(1):39-69. https://ijaps.usm.my/?page_id=4778. Accessed 15 Aug 2020. 
16. Efendi F, Chen CM, Nursalam N, Indarwati R, Ulfiana E. Lived experience of Indonesian nurses in Japan: a phenomenological study. Jpn J Nurs Sci. 2016;13:284-93. https://doi.org/10.1111/jins.12108.

17. Masselink LE, Daniel Lee S-Y. Government officials' representation of nurses and migration in the Philippines. Health Policy Plan. 2013;28:90-9. https://doi.org/10.1093/heapol/czs028.

18. Setyowati, Ohno S, Hirano YO, Yetti K. Indonesian nurses' challenges for passing the national board examination for registered nurse in Japanese: suggestions for solutions. Southeast Asian Stud. 2012;49:629-42. https:// kyoto-seas.org/wp-content/uploads/2012/07/490405.pdf. Accessed 15 Aug 2020.

19. Montayre JM, Montayre J. The global Filipino nurse: an integrative review of Filipino nurses' work experiences. J Nurs Manag. 2017;26(4):338-47.

20. Zhong Y, McKenna L, Copnell B. What are Chinese nurses' experiences whilst working overseas? A narrative scoping review. Int J Nurs Stud. 2017:74:101-11.

21. Al-Hamdan ZM, Al-Nawafleh AH, Bawadi HA, James V, Matiti M, Hagerty MB. Experiencing transformation: the case of Jordanian nurse immigrating to the UK. J Clin Nurs. 2015;24(15-16):2305-13.

22. Kawi J, Xu Y. Facilitators and barriers to adjustment of international nurses: an integrative review. Int Nurs Rev. 2009;56(2):174-83.

23. Newton S, Pillay J, Higginbottom G. The migration and transitioning experiences of internationally educated nurses: a global perspective. Nurs Manag. 2012;20:534-50.

24. Lujan J. Linguistic and cultural adaptation needs of Mexican American nursing students related to multiple-choice tests. J Nurs Educ 2008;47(7):327-30

25. Starr K. Nursing education challenges: students with English as an additional language. J Nurs Educ. 2009;48(9):478-87.

26. Kawaguchi Y, Hirano YO, Ogawa R, Ohno S. Exploring learning problems of Filipino nurse candidates working in Japan: based on the results of a practice national board examination of Japan given in English. Southeast Asian Stud. 2012;49:643-51. https://kyoto-seas.org/wp-content/uploa ds/2012/07/490406.pdf. Accessed 15 Aug 2020.

27. Tujimura M, Ishigaki K, Yamamoto-Mitani N, Fujita J, Katakura N, Ogata Y, et al. Cultural characteristics of nursing practice in Japan. Int J Nurs Pract. 2016;22(suppl. 1):56-64. https://doi.org/10.1111/ijn.12440.

28. Tsubota K, Ogawa R, Ohno S, Hirano YO. A study on the cost and willingness to recruit EPA foreign nurses and care workers in Japan: from the angle of hospitals and care facilities. Health Sci Res. 2015;27:45-53. https ://hdl.handle.net/10069/35044. Accessed 15 Aug 2020.

29. Hirano YO, Tsubota K. The economic and psychological burden to hospitals and care facilities of accepting EPA candidates in Japan. Int J Jpn Sociol. 2020;2016(25):40-53. https://doi.org/10.1111/ijjs.12044. Accessed 15 Aug 2020

30. Koseisourousyou: Indoneshia, Firipin, Betonamu kara no gaikokujin kangoshi, kaigofukushishi kouhosha no ukeire ni tsuite (Ministry of Health, Labour and Welfare: introducing Indonesian, Filipino, and Vietnamese nurses and certified care worker candidates). https://www.mhlw.go.jp/ stf/seisakunitsuite/bunya/koyou_roudou/koyou/gaikokujin/other22/ index.html. Accessed 27 Apr 2020. (Japanese only).

31. Hirano YO. "Double-Standard Employment" under JPEPA: the bilateral agreement and its implications for Filipino nurse migration to Japan. Asian Stud. 2016;52(2):33-54. https://www.asj.upd.edu.ph/mediabox/ archive/ASJ_52_2_2016/Hirano_Double_Standard_Employment_JPEPA _Filipino_Nurse_Migration_Japan.pdf. Accessed 15 Aug 2020.

32. Hosono Y. Accepting nurse and certified care worker candidates in Japan - how a bilateral policy decision is implemented at the administration level. Yokohama J Soc Sci. 2011;16(3):29-45. https ://ynu.repo.nii.ac.jp/?action=repository_action_common_downl oad\&item_id=3091\&item_no=1\&attribute_id=20\&file_no=1. Accessed 15 Aug 2020

33. Ohno S, Yoneno-Reyes M., Hirano YO. Chronic first aid: the scheme for the movement of Filipino nurses under the Japan-Philippines Economic Partnership Agreement (JPEPA), 2009-2016. Asian Stud. 2016;52(2):1-32. https://www.asj.upd.edu.ph/mediabox/archive/ASJ_52_2_2016/Ohno_ Chronic_First_Aid_Scheme_Filipino_Nurses_JPEPA.pdf. Accessed 15 Aug 2020.

34. Kokosaai Kousei Jikyo Dan. EPA ni motozuku kangoshi kouhosha no ukeire no tebiki (Japan International Corporation of Welfare Services. Guide book for employment of foreign nurses under the EPA). https://jicwels.or. jp/files/EPA_2021_N.pdf. Accessed 15 Aug 2020. (Japanese only).

35. Ogawa R, Hirano YO, Kawaguchi Y, Ohno S. A follow-up survey on hospitals and long-term care facilities accepting the first tach of Indonesian nurses/certified care worker candidates (1) analysis on the current status and challenges. Bul Kyushu Univ Asia Cent. 2010;5:85-98. https://catal og.lib.kyushu-u.ac.jp/opac_download_md/17928/p085.pdf. Accessed 15 Aug 2020.

36. Koseiroudousyou: Iryojuujisha no jukyuu ni kansuru kentoukai kangoshokuin jukyuu bunkakai chuukan torimatome (Ministry of Health, Labour and Welfare: supply and demand of medical personnel, nursing section working group mid-term report). https://www.mhlw.go.jp/conte nt/10805000/000567572.pdf. Accessed 27 Apr 2020. (Japanese only).

37. Koseiroudousyou: Kangoshokuin kakuho taisaku (Ministry of Health, Labour and Welfare: Provision against nurse shortage). https://www. mhlw.go.jp/stf/seisakunitsuite/bunya/0000095525.html. Accessed 27 Apr 2020. (Japanese only)

38. Japan Hospital Association. Notification on recruiting Chinese nurses (Chuugoku-jin kangoshi no byouin heno shuushoku ni tsuite) https:// www.hospital.or.jp/pdf/06_20150520_01.pdf. Accessed 15 Aug 2020. (Japanese only)

39. International Medical Human Recourse Foundation (Kokusai Iryou Jinzai Shien Kikou). https://www.kijsk.jp/. Accessed 15 Aug 2020. (Japanese only).

40. Japanese language proficiency test: N1-N5: summary of linguistic competence required for each level. https://www.jpt.jp/e/about/levelsumma ry.html. Accessed 15 Aug 2020. (Japanese only).

41. Knutsen HM, Fangen K, Žabko O. Integration and exclusion at work: Latvian and Swedish Agency Nurses in Norway. J Int Migr Integr. 2020;21:413-29. https://doi.org/10.1007/s12134-019-00660-5.

42. Bevan S. Britain accused of ignoring nurse-recruitment ban. Lancet. 2015;366(9501):1915-6. https://doi.org/10.1016/S0140-6736(05)67772-0.

43. Asahishimbun. Shin zairyushikaku meguri ronsen (New Immigration law on dispute). November 6, 2018 (Japanese only)

44. Koseiroudousyou: Yosan gaiyo youkyu no shuyou jikou (Ministry of Health, Labour and Welfare; the outline of budget for FY2016). https:// www.mhlw.go.jp/wp/yosan/yosan/16syokan/dl/02-01.pdf. Accessed 27 Apr 2020. (Japanese only).

45. Shakai hosyou kokumin kaigi dainikai bunkakai, Chukan torimatome (National committee for Social Security, Mid-term report). https://www. kantei.go.jp/jp/singi/syakaihosyoukokuminkaigi/chukan/siryou_4.pdf. Accessed 27 Apr 2020. (Japanese only).

46. Razavi S. Care going global? Afterword. In: Michel S, Peng I, editors. Gender, migration, and the work of care. Berlin: Springer International Publishing; 2017. p. 295-304.

\section{Publisher's Note}

Springer Nature remains neutral with regard to jurisdictional claims in published maps and institutional affiliations. 